\title{
1 Absence of intergroup discrimination in a naturalistic helping task
}

0

(1)

\section{Abstract}

Theory suggests that individuals are more willing to sustain personal costs to benefit ingroup members compared to outgroup members. Real-world tests of parochial attitudes have lagged behind decision-making tasks in controlled settings. We thus explored the validity of the in-group favouritism argument through a naturalistic helping task that entailed picking up 'lost letters' and posting them back to the addressee. The field experiment was conducted in rural Australia and the in-group/out-group distinction was established by varying the location of the receiver of the letter. We did not find any evidence of an in-group bias in this spontaneous helping task. The only variable that significantly affected the likelihood of a letter being returned was socioeconomic prosperity of towns, a finding that corroborates our previous research in an urban environment (Grueter et al. 2016; Westlake et al. 2019). The lack of intergroup discrimination can be explained with the material security hypothesis (Hruschka and Henrich 2013) according to which the existence of institutions (public services, global markets, social safety nets) that ensure material security and safe interaction with strangers lessens the need for investments in local community members to meet people’s basic needs.

Key words: in-group favouritism; parochial altruism; prosociality; lost letter; material security hypothesis 
Introduction

29

30

31

32

33

34

35

36

37

In-group favouritism, the tendency to more favourably treat members of one's own group than those in other groups, is a well-documented phenomenon in human societies (Brewer and Campbell 1976; Chen and Li 2009; Choi and Bowles 2007; Goette et al. 2006; Hewstone et al. 2002; Romano et al. 2017; Tajfel et al. 1971). In-group preferences can emerge with respect to a variety of groupings such as race and ethnicity (Nosek et al. 2002; Whitt and Wilson 2007), religon (Sosis and Ruffle 2003), political affiliation (Rand et al. 2008) and national identification (Mummendey et al. 2001). Ingroup favouritism is central to human sociality but its prevalence and precise manifestation can vary cross-culturally (Hruschka and Henrich 2013; see also Romano et al. 2017). A number of explanations for such in-group bias have been provided. One centres around the assumption that elevated in-group solidarity or prosociality confers a group advantage in a situation of intergroup conflict (Bowles et al. 2003; Boyd and Richerson 1990; Choi and Bowles 2007; García and van den Bergh 2011). Another explanation focuses on the benefits individuals incur from helping an in-group member in situations where members of demarcated groups frequently interact with one another; one key benefit is maintaining a positive reputation which increases the likelihood of positive reciprocity from in-group members (Kiyonari et al. 2000; Yamagishi et al. 1999;; see also Palmer 1991; but see Romano et al. 2017).

The application of field experiments (couched in an evolutionary framework) has lagged behind decision-making tasks in lab settings in documenting cooperative biases towards in-group members (for a meta-analysis see (Balliet et al. 2014).In this study, we aimed to unravel whether in-group favouritism is operational at the level of 
geographic locales. Research has shown that place identity can result from social comparisons and is correlated with demarcation of neighbourhoods (Lalli 1986) and higher evaluations of quality of residents’ own neighbourhood (in-group) (Bernardo and Palma-Oliveira 2016). Assuming that people exhibit such place identity with their town of residence, we set out to test if this concept fosters in-group favouritism. We explored the validity of the in-group favouritism argument through a naturalistic helping task that entailed picking up 'lost letters' and posting them back to the addressee (Milgram et al. 1965). The in-group/out-group distinction in this experiment was established by varying the location of the receiver of the letter.

To our knowledge, only four previous studies made explicit use of the lost letter technique to examine the prevalence of group biases in prosociality. Silva and Mace (2014) found evidence for the existence of in-group favouritism in Northern Ireland; people were more likely to return an in-group letter (letter addressed to an organisation representing the neighbourhood's majority religious group) than an out-group letter (letter addressed to an organisation representing the neighbourhood's minority group). (Koopmans and Veit 2014) examined the effects of religion and ethnicity on letter return rates but failed to find evidence of in-group favouritism when comparing return rates for letters from Turkish or Muslim organizations and from German and Christian organizations. (Bridges and Clark 2000) found no difference in return rate between incounty and out-county addressed letters. (Hellmann et al. 2015) showed that discriminatory behaviour towards out-groups was only seen when the letter recipient was a member of a stigmatized out-group, and that this effect was moderated by the perceived competence of the respective member of the stigmatized out-group. Our study also differs from previous lost letter studies in targeting a rural (as opposed to urban) population (but see Bridges and Clark 2000). 


\section{Methods}

78

79

80

81

\section{Data collection}

Field experiment

502 letters were distributed in 12 towns in Western Australia, exhibiting a range of different population sizes (for a map, see SI). Table S1 details each town used, its population size and the number of letters distributed in it. The median distance between the towns and Perth is $213 \mathrm{~km}$ (minimum: $122 \mathrm{~km}$; maximum: $2226 \mathrm{~km}$ ). The towns are not all connected by a major artery, as they lie in four different sections/directions. The number of letters distributed per town was dependent on the town's size. The maximum number of letters that could be distributed was dependent on the risk of residents becoming suspicious of the experiment. We scaled the number of letters dropped roughly per capita, with more letters dropped in fewer large towns and fewer letters dropped in more small towns. This resulted in 252 letters being distributed across all towns with a population size less than 5000 and 250 letters across all towns with a population larger than 5000. Half of the letters distributed in each town were addressed to a Perth address (the out-group address), and the other half were addressed to an intown address (the in-group address).

Towns were selected primarily based on the authors' knowledge of a resident of that town who was willing to volunteer their address, and the authors' ability to travel to the town. Towns with seasonal or 'fly in, fly out' work were excluded because of the potential lack of community with the residential population constantly changing. The population of many towns with seasonal work can double in the working season. This may greatly alter the sense of community in the town because of the large number of unfamiliar residents. Low residential stability may decrease an individual's trust of 
others and their sense of community (Abascal and Baldassari 2015), circumstances that are not conducive to the proliferation of parochial attitudes.

Letter drop technique was designed to control for encounter rates, minimize the mistake of the letter for garbage, and minimize the intervention of well-meaning postmen. Letter distribution locations were selected to be far away enough from each other so that the chance of one individual coming across multiple letters was extremely low. Letter distribution locations were visually selected to be of roughly equal distance from each other, to ensure an even spread across a town. Letter distribution locations were limited exclusively to residential streets. Locations also excluded construction sites, public transport stops, small businesses, schools and streets leading to public parks or exercise walks; this was done in order to limit the likelihood of a non-resident encountering the letter, and also to control for pedestrian foot traffic, ensuring that all letters had roughly the same chance of an individual encountering it. Areas in which a post box or post office was in sight were excluded as letter distribution locations to ensure that the effort required to return the letter was relatively consistent across all letter distribution locations. Letters were dropped exclusively on pedestrian pavements or at the end of driveways near the road if there was no footpath in that particular street. Letters were placed address-side up. Letters were surreptitiously distributed on Friday evenings to avoid postmen encountering the letters on weekdays. All letters were stamped and sealed. Envelopes contained a note to reduce suspicion in case they were opened, and were coded so that their exact drop location could be identified. Out of the twelve rural towns included in the study, eight had a PO Box as the within-town address, and four had a residential address. To ensure consistency within each town, the out-group (Perth) letters were also addressed to either a PO Box or a street address to match the in-town addressed letters. All Perth-addressed letters in 
every town were addressed to G. Westwood, which was determined to be suitable for the rural towns as none of the towns featured a Westwood household (White Pages n.d.). The name used for the in-town letters varied from town to town depending on the surnames of residents of the town. Names were checked using the residential White Pages to ensure that no one by that name lived in the town; this was done to reduce the likelihood of a resident passing on the letter to someone that they know by that name. The actual name of the person lending their letterbox in each town was not used because many people who lent their letterboxes were from well-known families in small towns with known reputations that may have influenced an individual's decision to return a letter.

Three weeks were allocated after posting and distributing the last group of letters to allow 'participants' time to return them. All letters were collected from the different return addresses at the conclusion of the experimental period. Each letter was treated as a separate data point and was determined to have been either returned or not returned. Information about each letter’s distribution method and distribution location was collated.

\section{Measures of socioeconomic status}

A concomitant study conducted in Perth revealed a strong positive effect of area-level socioeconomic status on the percentage of letter returned (Westlake et al. 2019) which prompted us to include socioeconomic status as a covariate in the statistical model (see below). Socioeconomic status was measured using the Australian Bureau of Statistics’ (ABS) measure IRSAD (Index of Relative Socio-economic Advantage and Disadvantage) (Australian Bureau of Statistics 2013; 2014). This measure consists of two sub-measures: Index of Economic Resources (IER) and Index of Education and 
151 Occupation (IEO). These measures were obtained for each suburb, and also smaller

152 areas within each suburb called statistical areas level 1 (SA1) (Australian Bureau of

153 Statistics 2011).

154

155

\section{Data analysis}

156 To address the effect of population size and group biases within rural towns, a

157 Generalized Linear Mixed Model (GLMM) with binomial error structure and logit link

158 function was conducted with the following fixed effects: in vs. out-group (whether a

159 letter was addressed to an in-town address or a Perth (out-group) address), population

160 size, IRSAD at the SA1 level, and post or letterbox (whether the address written on the

161 letter was a post office box or a street letterbox). PO Box or letterbox was included to

162 control for any effect that it may have on whether a letter would be returned or not (for

163 example, individuals may have favoured letters addressed to letterboxes over letters

164 addressed to PO Boxes). The number of post boxes in the town was not included due to

165 its high collinearity with town size. As an anti-pseudoreplication measure, the town

166 itself was included in the model as a random effect. GLMMs were computed with the

167 lme4 package (Bates et al. 2015) in the statistical software R (R Core Team 2014)

168 version 3.3.1.

169

170 Ethics

171 Ethics was granted by the University of Western Australia Human Research Ethics

172 Committee in accordance with the National Statement on Ethical Conduct in Human

173 Research (National Health and Medical Research Council 2015; reference number

$174 \mathrm{RA} / 4 / 1 / 8257)$.

175 


\section{Results}

177 Of the 502 letters dropped in rural towns, 224 (44.6\%) were picked up by a passer-by 178 and posted to the address written on the envelope. Of these 224 letters, 113 had been

179 addressed to an out-group recipient and 111 to an in-group recipient (see also tables S1 180 and S2). Based on the results from the logistic GLMM, we were unable to reject the 181 hypothesis that the address of a letter (in-group [in-town] vs. out-group [Perth]) was not 182 a predictor of whether a letter was returned or not. IRSAD significantly positively 183 affected the probability of a letter being returned. We failed to find a significant effect 184 of population size of the town on the likelihood of a letter being returned. Additionally, 185 post or letterbox was not significant in the model, suggesting that the nature of the 186 address written on the letter (whether it was a PO Box or a residential letterbox) did not 187 affect the likelihood of a letter being returned. Many of the returned letters contained 188 hand-written notes on them such as "Hope this letter finds its way home" and "I found 189 this letter on the road but have posted it for the person", indicating that the sender 190 expressed prosocial intent.

Table 1. Results from a GLMM with letter return as the dependent variable and address 193 of a letter (in-town vs. out of town), population size, IRSAD (Index of Relative Socioeconomic Advantage and Disadvantage), and PO Box vs. Street (i.e. whether the intown and out of town addresses were PO Boxes or street addresses) as independent variables. The words in parentheses are the levels for which the predictor was estimated. 197

\begin{tabular}{|l|l|l|l|}
\hline Variables & Estimate & Standard Error & $\mathbf{p}$ \\
\hline (Intercept) & -6.159 & 1.594 & \\
\hline
\end{tabular}




\begin{tabular}{|l|l|l|l|}
\hline $\begin{array}{l}\text { Group bias (out- } \\
\text { group) }\end{array}$ & 0.093 & 0.195 & 0.635 \\
\hline Population size & -0.000 & 0.000 & 0.522 \\
\hline IRSAD & 0.006 & 0.002 & $\leq 0.001$ \\
\hline $\begin{array}{l}\text { PO Box vs. Street } \\
\text { (PO Box) }\end{array}$ & 0.793 & 0.654 & 0.225 \\
\hline
\end{tabular}

\section{Discussion}

Contrary to our expectation, this field experiment examining cooperativeness did not reveal the existence of an in-group bias in rural Western Australia ${ }^{1}$. The fact that we had a priori excluded towns with seasonal or 'fly in, fly out' work (with presumably less community cohesion and parochialism) and still did not find parochial cooperation strengthens the results from this study. In line with our previous studies (Westlake et al. 2019; Grueter et al. 2016) and work by others (e.g. Holland et al. 2012; Nettle 2015;

207 Silva and Mace 2014), we show that area-level socioeconomic status was strongly 208 associated with helping behaviour.

A number of reasons may be responsible for the lack of in-group solidarity in our study. First, the costs inherent in the altruistic act of posting a letter are relatively

211 low, thus increasing the likelihood that people would not differentiate among groups 212 and hence engage in unbiased helping behaviour. Second, building on social identity 213 theory (Tajfel 1978) a certain level of in-group identification or sense of belonging to a

\footnotetext{
${ }^{1}$ It is possible that the group behaviours observed in this experiment are not entirely reflective of community attitudes on helping in-group or out-group members. Changing the address written on the letter is perhaps not a completely valid measure of willingness to help in-group members compared to out-group members. Individuals who encounter letters with out-of-town addresses will likely assume that they were dropped by someone who lives in the town (especially in isolated towns). Therefore, by returning an out-of-town letter, individuals may believe that they are still helping an in-group member (the individual who dropped it).
} 
community or locale is needed for in group bias to materialize (Kelly 1993; Nighur and Cinnirella 2007). Without conducting systematic interviews or administering surveys it is unclear how strongly people identify themselves with their locale.

Third, anecdotally, none of the people whose addresses we used felt any animosity towards Perth. The lack of an existing conflict among the groups/social settings studied may have diminished the expression of parochial attitudes (cf. (Bauer et al. 2014). One lost letter experiment conducted in an area rife with inter-group tensions - Northern Ireland - (Silva and Mace 2014) found that conflict was associated with reduced donations to out-group institutions and the return of out-group letters, but there was no increase in in-group altruism.

A final possibility is that all-inclusive cooperative attitudes reflect the existence of friendship/business ties which may not be confined to local group, or attempts at keeping open channels of mutually beneficial exchange with strangers (Grueter and White 2014; Schaub 2017). Pisor and Gurven (2016), for example, showed that valuation of out-group strangers can be positive if there is potential for between-group trade. In a similar vein, the results are consistent with the existential or material security hypothesis which posits that people with access to institutions such as public services, global markets and social safety nets tend to less parochial because they can meet their basic needs through impartial interactions with strangers. People without such institutions, on the other hand, must rely on local community members as an alternative form of social insurance (Hruschka et al. 2014; Hruschka and Henrich 2013; Norris and Inglehart 2011; but see Romano et al. 2017). The inhabitants of the towns included in this experiment in rural Western Australia experience relatively high levels of resource security and high-quality government services, which makes impartial investments in regards to groups more likely. Comparative cross-cultural analyses are needed to 
239 establish that material security obviates the need for in-group/out-group discrimination 240 in a naturalistic task using real-life measures of cooperative intent (for a behavioural 241 experimental approach addressing the effects of institutional quality and material 242 security on in-group favouritism, see (Hruschka et al. 2014)).

\section{References}

245 We would like to thank the anonymous reviewer for two rounds of very thorough and 246 valuable comments on this manuscript.

\section{References}

249 Abascal, M., \& Baldassarri, D. (2015). Love thy neighbor? Ethnoracial diversity and trust reexamined. American Journal of Sociology, 121, 722-782.

Australian Bureau of Statistics. (2014). IRSAD, Australian Government. Available from: http://www.abs.gov.au/ausstats/abs@.nsf/Lookup/2033.0.55.001main+features1 00042011/ [9 May 2016].

Australian Bureau of Statistics. (2013). Census of population and housing: Socioeconomic indexes for areas (SEIFA), Australia, 2011, cat. no. 2033.0.55.001, ABS, Canberra. Available from: http://www.abs.gov.au/AUSSTATS/abs@.nsf/DetailsPage/2033.0.55.0012011? OpenDocument. [7 May 2016].

Australian Bureau of Statistics. (2011). Statistical Area Level 1 (SA1), Australian Government. Available from: http://www.abs.gov.au/ausstats/abs@.nsf/0/7CAFD05E79EB6F81CA25780100 0C64CD?opendocument/. [9 May 2016]. 
Balliet, D., Wu, J., \& De Dreu, C. K. W. (2014). Ingroup favoritism in cooperation: A meta-analysis. Psychological Bulletin, 140, 1556.

Bates, D., Maechler, M., Bolker, B., \& Walker, S. (2015). Fitting linear mixed effects models using lme4. Journal of Statistical Software, 67, 1-48

Bauer, M., Cassar, A., Chytilová, J., \& Henrich, J. (2014). War’s enduring effects on the development of egalitarian motivations and in-group biases. Psychological Science, 25, 47-57.

Bernardo, F. \& Palma-Oliveira J.-M. (2016). Urban neighbourhoods and intergroup relations: The importance of place identity. Journal of Environmental Psychology, 45, 239-251.

Bowles, S., Choi, J-K., \& Hopfensitz, A. (2003). The co-evolution of individual behaviors and social institutions. Journal of Theoretical Biology, 223, 135-147.

Boyd, R., \& Richerson, P. J. (1990). Group selection among alternative evolutionarily stable strategies. Journal of Theoretical Biology, 145, 331-342.

Brewer, M. B., \& Campbell, D. T. (1976). Ethnocentrism and intergroup attitudes: East African Evidence. Beverly Hills CA: Sage.

Bridges, F. S., \& Clark, S. M. (2000). Differences in lost letter responses from smaller rural communities. North American Journal of Psychology, 2, 121-126.

Chen, Y., \& Li, S. X. (2009). Group identity and social preferences. American Economic Review, 99, 431-457.

Choi, J.-K., \& Bowles, S. (2007). The coevolution of parochial altruism and war. Science, 318, 636-640.

García, J., \& van den Bergh, J. C. (2011). Evolution of parochial altruism by multilevel selection. Evolution and Human Behavior, 32, 277-287. 
Goette, L., Huffman, D., \& Meier, S. (2006). The impact of group membership on cooperation and norm enforcement: Evidence using random assignment to real social groups. American Economic Review, 96, 212-216.

Grueter, C. C., \& White, D. R. (2014). On the emergence of large-scale human social integration and its antecedents in primates. Structure and Dynamics:eJournal of Anthropological and Related Science, 7: 1-27.

Grueter, C. C., Ingram, J. A., Lewisson, J. W., Bradford, O. R., Taba, M., Coetzee, R. E., \& Sherwood, M. A. (2016). Human altruistic tendencies vary with both the costliness of selfless acts and socioeconomic status. PeerJ, 4, e2610.

Hellmann, J. H., Berthold, A., Rees, J. H., \& Hellmann, D. F. (2015). “A letter for Dr. Outgroup": On the effects of an indicator of competence and chances for altruism toward a member of a stigmatized out-group. Frontiers in Psychology, $6,1422$.

Hewstone, M., Rubin, M., \& Willis, H. (2002). Intergroup bias. Annual Review of Psychology, 53, 575-604.

Holland, J., Silva, A. S., \& Mace, R. (2012). Lost letter measure of variation in altruistic behaviour in 20 neighbourhoods. PLOS ONE, 7, e43294.

Hruschka, D. J., \& Henrich, J. (2013). Institutions, parasites and the persistence of ingroup preferences. PLOS ONE, 8, e63642.

Hruschka, D., Efferson, C., Jiang, T., Falletta-Cowden, A., Sigurdsson, S., McNamara, R., Sands, M., Munira, S., Slingerland, E., \& Henrich, J. (2014). Impartial institutions, pathogen stress and the expanding social network. Human Nature, 25, 567-579.

Kelly, C. (1993). Group identification, intergroup perceptions and collective action. European Review of Social Psychology, 4, 59-83. 
Kiyonari, T., Tanida, S., \& Yamagishi, T. 2000. Social exchange and reciprocity: Confusion or a heuristic? Evolution and Human Behavior, 21, 411-427.

Koopmans, R., \& Veit, S. (2014). Cooperation in Ethnically Diverse Neighborhoods: A Lost-Letter Experiment. Political Psychology, 35, 379-400.

Lalli, M. (1986). Urban identity. In D. Canter, J. C. Jesuino, L. Soczka, \& G. M. Stephenson (Eds.), Environmental social psychology (pp. 303-319). Dordrecht: Kluwer Academic Publishers.

Milgram, S., Mann, L., \& Harter, S. (1965). The lost-letter technique: A tool of social research. Public Opinion Quarterly, 29, 437-438.

Mummendey, A., Klink, A., Brown, R. (2001). Nationalism and patriotism: national identification and outgroup rejection. British Journal of Social Psychology, 40, 159-172.

Nettle, D. (2015). Tyneside neighbourhoods: Deprivation, social life and social behaviour in one British city. Cambridge: Open Book Publishers.

Nigbur, D., \& Cinnirella, M. (2007). National identification, type and specificity of comparison and their effects on descriptions of national character. European Journal of Social Psychology, 37, 672-691.

Norris, P., \& Inglehart, R. (2011). Sacred and secular: Religion and politics worldwide. Cambridge: Cambridge University Press.

Nosek, B. A., Banaji, M., \& Greenwald, A. G. (2002). Harvesting implicit group attitudes and beliefs from a demonstration web site. Group Dynamics: Theory, Research, and Practice, 6, 101-115.

Palmer, C. T. (1991). Kin-selection, reciprocal altruism, and information sharing among Maine lobstermen. Ethology and Sociobiology, 12, 221-235. 
Pisor, A. C., \& Gurven, M. (2016). Risk buffering and resource access shape valuation of out-group strangers. Scientific Reports, 6, 30435.

R Core Team. (2014). R: A language and environment for statistical computing. R Foundation for Statistical Computing, Vienna, Austria.

Rand, D. G., Pfeiffer, T., Dreber, A., Sheketoff, R. W., Wernerfelt, N. C. \& Benkler, Y. (2009). Dynamic remodeling of in-group bias during the 2008 presidential election. Proceedings of the National Academy of Sciences USA, 106, 61876191.

Romano, A., Balliet, D., Yamagishi, T., Liu, J. H. (2017). Parochial trust and cooperationacross 17 societies. Proceedings of the National Academy of Sciences, 114, 12702-12707.

Schaub, M. (2017). Threat and parochialism in intergroup relations: Lab-in-the-field evidence from rural Georgia. Proceedings of the Royal Society of London B: Biological Sciences, 284, 20171560.

Silva, A. S., \& Mace, R. (2014). Cooperation and conflict: field experiments in Northern Ireland. Proceedings of the Royal Society of London B: Biological Sciences, 281, 20141435.

Sosis, R. \& Ruffle, B. J. (2003). Religious ritual and cooperation: testing for a relationship on Israeli religious and secular Kibbutzim. Current Anthropology, 44, 713-721.

Tajfel, H. (1978). Differentiation between social groups. London: Academic Press.

Tajfel, H., Billig, M. G., Bundy, R. P., \& Flament, C. (1971). Social categorization and intergroup behaviour. European Journal of Social Psychology, 1, 149-178.

Whitt, S. \& Wilson, R. K. (2007). The dictator game, fairness and ethnicity in postwar Bosnia. American Journal of Political Science, 51, 655-668. 
362 Yamagishi, T., Jin, N., \& Kiyonari, T. (1999). Bounded generalized reciprocity: Ingroup boasting and ingroup favoritism. Advances in Group Processes, 16, 161-197.

365 Westlake, G., Coall, D., \& Grueter, C. C. (2019). Educational attainment is associated with unconditional helping behavior. Evolutionary Human Sciences 1, e15 
